\title{
DMA and Conductivity Studies in PVA:NH SCN:DMSO:MWNT Nanocomposite Polymer Dried Gel Electrolytes
}

\author{
S. L. Agrawal ${ }^{1}$ and Neelesh Rai ${ }^{2}$ \\ ${ }^{1}$ SSI Laboratory, Department of Physics, APS University, Rewa, Madhya Pradesh, India \\ ${ }^{2}$ Department of Physics, AKS University, Satna, Madhya Pradesh, India \\ Correspondence should be addressed to Neelesh Rai; neeleshssi@gmail.com
}

Received 15 November 2014; Revised 22 February 2015; Accepted 2 March 2015

Academic Editor: Lianxi Zheng

Copyright (c) 2015 S. L. Agrawal and N. Rai. This is an open access article distributed under the Creative Commons Attribution License, which permits unrestricted use, distribution, and reproduction in any medium, provided the original work is properly cited.

\begin{abstract}
This paper deals with findings on dynamic mechanical analysis (DMA) and ion-conduction behavior of MWNTs (multiwall carbon nanotubes) doped PVA: $\mathrm{NH}_{4} \mathrm{SCN}$ :DMSO dried gel electrolyte system prepared for four filler concentrations (2, 4, 6 \& 8 wt\%) by solution cast technique. XRD measurements reveal enhancement in amorphous behavior of composite gel electrolyte upon incorporation of filler particles. Better mechanical stability is noticed in the composite system upon dispersal of MWNT along with presence of dynamic $T_{g}$ during DMA measurements. Enhancement in ionic conductivity has been noticed with an optimum value of $4.5 \times 10^{-3} \mathrm{Scm}^{-1}$ for $6 \mathrm{wt} \%$ MWNTs filled composite electrolyte. Composite system exhibits combination of Arrhenius and Vogel-Tammam-Fulcher (VTF) behavior in temperature dependent conductivity study. The a.c. conductivity response seems to follow universal power law.
\end{abstract}

\section{Introduction}

During the past two decades, there has been a progressively increasing interest in ionically conducting membranes possessing properties that enables them to replace the conventional liquid electrolyte used as separators in electrochemical devices [1]. In designing a novel polymer electrolyte, emphasis is placed on increasing the amorphous content in the polymer which assists fast ion motion while maintaining its mechanical stability [2]. Various polymer matrix systems that have been studied for this purpose include PEO (polyethylene oxide) $[1,3,4]$, PVA (polyvinyl alcohol) $[2,5]$, PVdF (polyvinylidene fluoride) [6], and PVP (Poly vinyl pyrrolidone) [7]. Among these polymer hosts, PVA has been prominently studied due to its excellent biocompatibility, electrochemical stability, and solvent-swollen ability $[2,5]$. Further, this polymer contains hydroxyl groups attached to methane carbons which are active sites for complexation with various salts and acids [8]. Owing to the possibility of achieving maximal ionic conduction with protons $/ \mathrm{NH}_{4}^{+}$ ions as transporting specie in polymer electrolyte systems, impetus has also been given to development of proton conducting polymer electrolytes in recent times. Awadhia and Agrawal [5] have reported ionic conductivity of the order of $10^{-3} \mathrm{Scm}^{-1}$ in Polyvinyl alcohol-ammonium thiocyanatedimethyl sulphoxide (PVA- $\mathrm{NH}_{4} \mathrm{SCN}-\mathrm{DMSO}$ ) dried gel electrolyte. However, it is difficult to use such a system in devices due to insufficient ionic conductivity and poor mechanical stability at ambient temperature when samples are kept over prolonged time periods. These drawbacks have been reduced considerably by using a third component in pristine polymer electrolytes matrix leading to emergence of composite polymer electrolytes in recent past $[9,10]$.

After the advent of nanotechnology, researchers have also used dispersion of a third component of nanodimensions in pristine polymer electrolytes in a bid to circumvent problems cited above. Thus, efforts have been directed in recent past to develop high performance nanocomposite polymer electrolytes [11, 12]. Generally, nanostructural particles like ceramics $[12,13]$ and carbon nanotubes [14] have not only been shown to improve the mechanical properties of gel and solid polymer electrolyte membranes and their nanofibers but they have also provided improved conductivities to allow their usage in sensors, super capacitors, batteries, electronic 
components, and so forth [15]. Carbon nanotubes (CNTs) are considered as an ideal reinforcement material for polymer nanocomposites [14, 15], as the mechanical properties of the polymer composites are strongly influenced by their morphology and crystallization behaviour [16-18]. Though CNT is electronic in nature, the surface groups present are likely to promote charge dissociation leading to improved ionic conductivity. Hence, it is very instructive to characterize CNT-reinforced proton conducting polymer nanocomposite electrolytes. Based on these considerations, efforts have been made in the present work to develop a sufficiently dry free standing proton conducting composite gel membranes of PVA: $\mathrm{NH}_{4} \mathrm{SCN}$ dispersed with multiwall carbon nanotubes (MWNTs) and characterise them structurally and electrically.

\section{Materials and Methods}

In this study, PVA (average molecular weight 124,000186,000 Aldrich make), ammonium thiocyanate $\left(\mathrm{NH}_{4} \mathrm{SCN}\right)$, AR grade sd. fine chem. make, and aprotic solvent dimethyl sulphoxide (DMSO) Merk limited, Mumbai, make were chosen for synthesis of nanocomposite polymer electrolyte (NCPE). MWNT used in the study was obtained from Aldrich, CAS Number: 308068-56-6, possessing average diameter 110-170 $\mathrm{nm}$ and length 6-9 $\mu \mathrm{m}$. PVA was dispersed in $1 \mathrm{M}$ salt solution of $\mathrm{NH}_{4} \mathrm{SCN}$ in DMSO in different stoichiometric ratios to form pristine electrolyte (PE). Composite polymer electrolytes (CPE) were prepared by adding MWNTs in $\mathrm{PE}$ solution in different weight fractions (2 to $8 \mathrm{wt} \%$ ) followed by thorough mixing for nearly 8 hours at $45^{\circ} \mathrm{C}$ on a magnetic stirrer. The so obtained viscous solution was poured in polycarbonate pettridishes to gellify. Containers were covered with Al-foil to avoid contamination and kept for 7-10 days. After syneresis gel in the form of thick film was obtained. The films were taken out and dried at $60^{\circ} \mathrm{C}$ in air for 15 days for exudation of unwanted liquid to obtain dried composite polymer gel electrolyte films.

Dynamic mechanical analysis (DMA) was carried out on a dynamic mechanical spectrometer (model DMS 6100 SSI Nanotechnology Inc., USA). DMA runs were recorded at $3^{\circ} \mathrm{C}$ heating rate. Measurement of storage modulus $\left(\mathrm{E}^{\prime}\right)$, loss modulus $\left(\mathrm{E}^{\prime \prime}\right)$, and $\tan \delta$ of dried gel electrolyte samples was performed in compression mode at $10 \mathrm{~Hz}$ frequency in the temperature range $25^{\circ} \mathrm{C}$ to $200^{\circ} \mathrm{C}$.

$\mathrm{X}$-ray diffraction (XRD) patterns of films were recorded on X-ray diffractometer (RIGAKU, JAPAN make, model MINIFLEX-II). The diffraction patterns were recorded at room temperature $\left(\sim 30^{\circ} \mathrm{C}\right)$ for the Bragg angle $(2 \theta)$ varying from $2^{\circ}$ to $90^{\circ}$ with $\lambda=1.541 \AA$.

The complex-impedance measurements were carried out with help of a computer controlled Hioki (Japan) make LCR meter (Model 3520). The solid composite electrolyte was sandwiched between two platinum electrodes to measure electrical conductivity in the frequency range $40 \mathrm{~Hz}-100 \mathrm{kHz}$ at different temperatures ranging in between $30^{\circ} \mathrm{C}$ and $100^{\circ} \mathrm{C}$. a.c. conductivity has been calculated from impedance data using the relation

$$
\sigma_{\mathrm{ac}}=\varepsilon_{o} \omega \varepsilon_{r} \tan \delta
$$

where $\varepsilon_{r}$ (relative permittivity) $=C / C_{o}, \varepsilon_{o}$ is the permittivity of the free space, $\omega=2 \pi f, f$ is the frequency of the applied field.

\section{Results and Discussion}

3.1. Dynamic Mechanical Analysis. Occurrence of molecular mobility transitions, such as dynamic glass transition temperature $\left(T_{g}\right)$ and other mechanical relaxations can be studied with the help of $\varepsilon^{\prime}, \varepsilon^{\prime \prime}$ and Tan $\delta$ versus $T$ plot. Variation in $\mathrm{E}^{\prime}$ (storage modulus), $\mathrm{E}^{\prime \prime}$ (loss modulus) and Tan $\delta$ (loss tangent or damping factor) with temperature for composite and pristine electrolyte films are shown in Figures 1 and 2. It is apparent from Figure 1 that storage modulus $\mathrm{E}^{\prime}$ enhances in general upon introduction of filler particles in matrix electrolyte below $100^{\circ} \mathrm{C}$ indicating improvement in mechanical stability of the system. However, the peak flexural storage modulus diminishes with increasing CNT content. Careful examination of modulus data shows that CNT soaked films give rise to dynamic $T_{g}$ of composite system coupled with transition related to melting of composite electrolyte system in the temperature range $120-160^{\circ} \mathrm{C}$. Existence of dynamic $T_{g}$ in composite system dispersed with particles of nanodimensions has been earlier reported by Tsagaropoulos and Eisenberg [14]. Increasing CNT content shifts melting related peaks to lower temperature and ultimately convolutes the separate transitions into a broader transition at $6 \mathrm{wt} \%$ CNT. When CNT content is added in excess of $6 \mathrm{wt} \%$ it causes reappearance of CNT and composite related transitions. These observations show maximum intercalation of $6 \mathrm{wt} \%$ CNT content in matrix electrolyte and suggest that the mechanical stability of nanocomposites increases with filler loading till $6 \mathrm{wt} \%$. Simultaneously, the decreasing nature of storage modulus beyond $6 \mathrm{wt} \%$ MWNTs, suggest loss in molecular mobility of the polymer matrix. This can be attributed to agglomeration of filler particles (caused by Vander Waal force among nanotubes) rendering large surface area, which diminishes filler-polymer interaction [19]. It is probably due to the presence of salt $\left(\mathrm{NH}_{4} \mathrm{SCN}\right)$ ions intercalated with nanotubes within polymer matrix affecting the crystallisation process and thus they play a role of plasticization effect [20].

Figure 2(a) shows the variation of loss modulus with temperature for different MWNTs filler concentration in pristine electrolyte. A small broad transition around $50^{\circ} \mathrm{C}$ is noticed in $\mathrm{E}^{\prime \prime}$ view graph (present in all samples) which is essentially due to interaction of DMSO with PVA [5]. Pure PVA powder used in the present investigation possesses a glass transition of nearly $\sim 85^{\circ} \mathrm{C}$ and has been reported in one of our earlier papers [8]. This transition shifts towards higher temperature in nanocomposite polymer electrolyte with MWNT level upto $4 \mathrm{wt} \%$ and transforms into welldefined broad peak in $\mathrm{E}^{\prime \prime} \& \tan \delta$ reflecting dynamic $T_{g}$ of PVA in NCPE and also referred as a $\alpha$ relaxation [11]. Further, a small shoulder around $98^{\circ} \mathrm{C}$ has been traced in $\mathrm{E}^{\prime \prime}$. This can be correlated to presence of water formed in the process of interaction of DMSO with PVA and has been reported earlier [11]. This transition shifts on temperature scale towards lower 
TABLE 1: Peak values of loss modulus at $5 \mathrm{~Hz}$ for different concentration of MWNT filled PVA: $\mathrm{NH}_{4} \mathrm{SCN}_{\mathrm{N}}$ nanocomposite polymer electrolytes.

\begin{tabular}{|c|c|c|c|c|c|}
\hline \multirow{2}{*}{ Samples composition } & \multicolumn{5}{|c|}{ Transition temperatures } \\
\hline & $P_{1}$ & $P_{2}$ & $P_{3}$ & $P_{4}$ & $P_{5}$ \\
\hline PVA: $\mathrm{NH}_{4} \mathrm{SCN}$ polymer gel electrolyte & 102 & 119.1 & 136 & 143 & 162 \\
\hline $\begin{array}{l}\text { PVA:NH} \mathrm{NH}_{4} \mathrm{SCN}: 2 \mathrm{wt} \% \mathrm{MWNT} \\
\text { filled composite gel electrolyte }\end{array}$ & 98.8 & 123.6 & 137.1 & 147 & 160 \\
\hline $\begin{array}{l}\text { PVA: } \mathrm{NH}_{4} \mathrm{SCN}: 4 \mathrm{wt} \% \mathrm{MWNT} \\
\text { filled composite gel electrolyte }\end{array}$ & 96.3 & 122 & 138 & 150 & 163 \\
\hline $\begin{array}{l}\text { PVA: } \mathrm{NH}_{4} \mathrm{SCN}: 6 \mathrm{wt} \% \mathrm{MWNT} \\
\text { filled composite gel electrolyte }\end{array}$ & 87.6 & 119.2 & $\cdots$ & 144 & 159 \\
\hline $\begin{array}{l}\text { PVA: } \mathrm{NH}_{4} \mathrm{SCN}: 8 \mathrm{wt} \% \text { MWNT } \\
\text { filled composite gel electrolyte }\end{array}$ & 103.6 & 122.2 & 136 & 148 & 162 \\
\hline
\end{tabular}

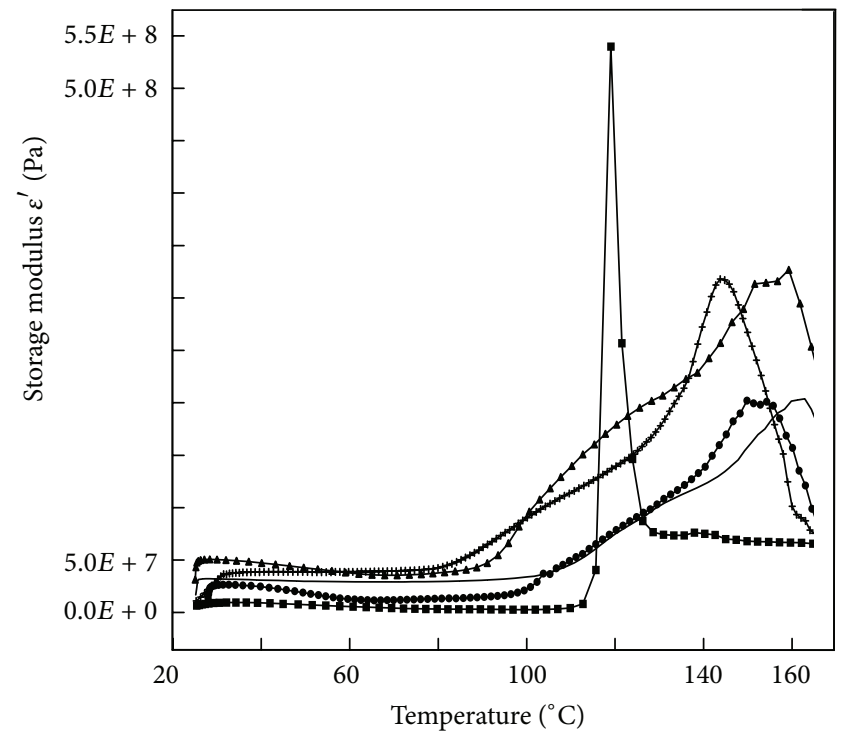

FIGURE 1: Storage modulus as a function of the frequency of oscillation and temperature for unfilled (घ), $2 \mathrm{wt} \%(\boldsymbol{\Delta}), 4 \mathrm{wt} \%(\bullet)$, $6 \mathrm{wt} \%(++)$, and $8 \mathrm{wt} \%(-)$ MWNT filled PVA: $\mathrm{NH}_{4} \mathrm{SCN}: \mathrm{DMSO}$ nanocomposite gel electrolytes at $05 \mathrm{~Hz}$.

temperature with increase of MWNT contents (Table 1). The loss spectra of pristine complex show a well-defined peak around $120^{\circ} \mathrm{C}$. This can be assigned to presence of bound water in pristine system. Existence of this water has also been shown earlier [11]. A shoulder relaxation around $150^{\circ} \mathrm{C}$ gives reflection of the presence of uncomplexed salt in electrolyte on account of melting of salt [12]. The loss spectra show a welldefined peak around $160^{\circ} \mathrm{C}$ (Table 1 ). This can be assigned to complexation caused by interaction among components and therefore referred to as composite $T_{g}$ of NCPE system. Kerr et al. [21] have reported that when the fillers are of nanodimension and the concentration of filler particles is optimum, a composite or second $T_{g}$ may be observed in dynamic mechanical behaviour at higher temperatures. The composite $T_{g}$ is attributed to $\sigma$ relaxation. The $\sigma$ relaxation peak is possibly due to breakage of hydrogen bonding between polymer chains which induces long segmental chain movement in the amorphous area $[1,5]$.
Figure 2(b) which shows the tangent loss plot of dried films of composite electrolyte is a manifestation of the results obtained in Figure 2(b). In this graph, a major and few other shoulder peaks appear for all stoichiometric ratios. These peaks also show the presence of $\alpha$ and $\sigma$ relaxations as discussed earlier.

3.2. XRD Studies. The XRD patterns of MWNTs filled polymer composite electrolyte films along with pristine electrolyte and pristine components are shown in Figure 3. These patterns show in general an increase in amorphousness of polymer electrolytes on addition of MWNT filler. This is reflected from the decrease in intensity for all the major peaks along with increase in broadening. Intercalation of CNT contents with electrolyte matrix results in such a behavior. Two peaks appear in the diffractogram of pristine electrolyte (Inset Figure 3(d)), which do not correspond to either $\mathrm{NH}_{4} \mathrm{SCN}$ salt or PVA and thus has been earlier correlated to formation of PVA: $\mathrm{NH}_{4} \mathrm{SCN}$ complex. Further, these observations also corroborate the results of Awadhia and Agrawal [5] who have reported interaction of $\mathrm{NH}_{4} \mathrm{SCN}$ with PVA leading to formation of PVA- $\mathrm{NH}_{4} \mathrm{SCN}$ complex. When $2 \mathrm{wt} \%$ MWNT filler is loaded in pristine electrolyte (Figure 3(e)), the peaks seem to broaden up in XRD profile besides emergence of a broad peak around $26.1^{\circ}$. It is apparent from comparison of XRD profile "a" (inset Figure 3(a)) with profile "e" that $26.1^{\circ}$ peak in diffractogram "e" essentially corresponds to MWNT [14]. Further, the broadening seems to result from intercalation of MWNT in electrolyte matrix. Though complex related main peak shifts towards lower $2 \theta$ values as a result of polymer salt filler interaction, existence of MWNT related XRD peak shows that MWNT essentially acts as passive filler and is responsible only for change in film morphology [22]. On addition of $4 \mathrm{wt} \% \mathrm{MWNT}$ content (Figure 3(f)), the main peak (PVA: $\mathrm{NH}_{4} \mathrm{SCN}$ complex related peak) is seen to shift to higher $2 \theta$ value along with increase in broadness and further loss of intensity. This can once again be attributed to polymer-salt-filler interaction [22-24]. On further extending MWNT loading to 6 and $8 \mathrm{wt} \%$ (Figure 3 (g) and $(\mathrm{h})$ ), complex related peak again shifts towards lower $2 \theta$ value with increasing intensity. At higher concentration of MWNT (Figure 3(h)), the characteristic reflections of filler start reappearing because of its segregation. From X-ray 


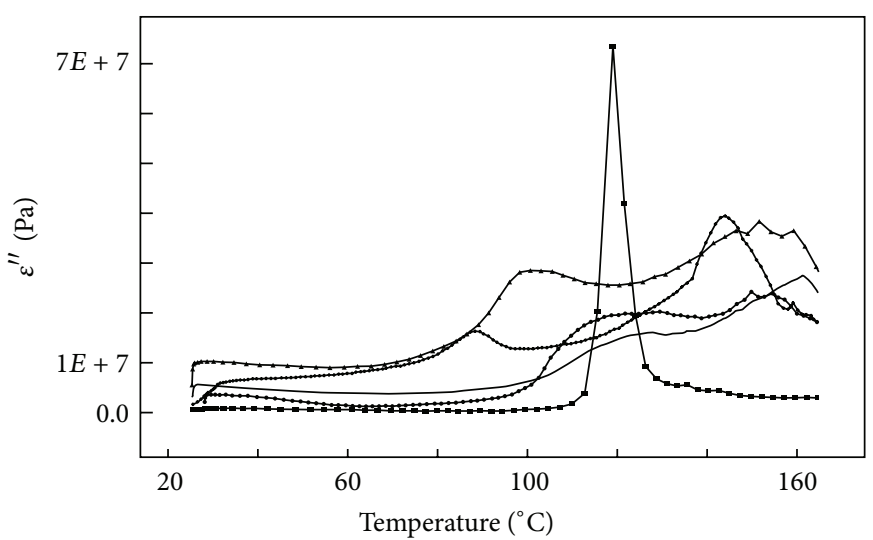

(a)

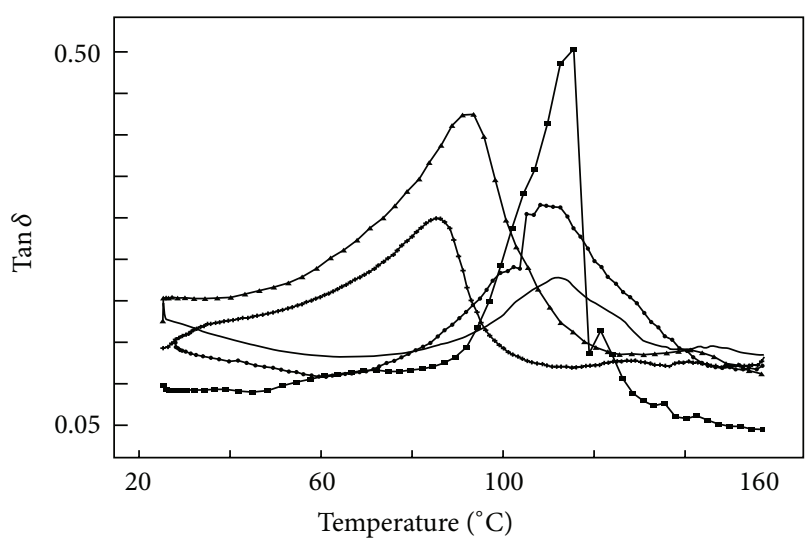

(b)

Figure 2: (a \& b) The frequency of oscillation and temperature for unfilled (घ), $2 \mathrm{wt} \%(\mathbf{\Delta}), 4 \mathrm{wt} \%(\bullet), 6 \mathrm{wt} \%(++)$, and $8 \mathrm{wt} \%(-)$ MWNT filled PVA: $\mathrm{NH}_{4} \mathrm{SCN}$ :DMSO nanocomposite electrolytes for Loss modulus at $05 \mathrm{~Hz}$ and Mechanical damping $\tan \delta$ at $05 \mathrm{~Hz}$.

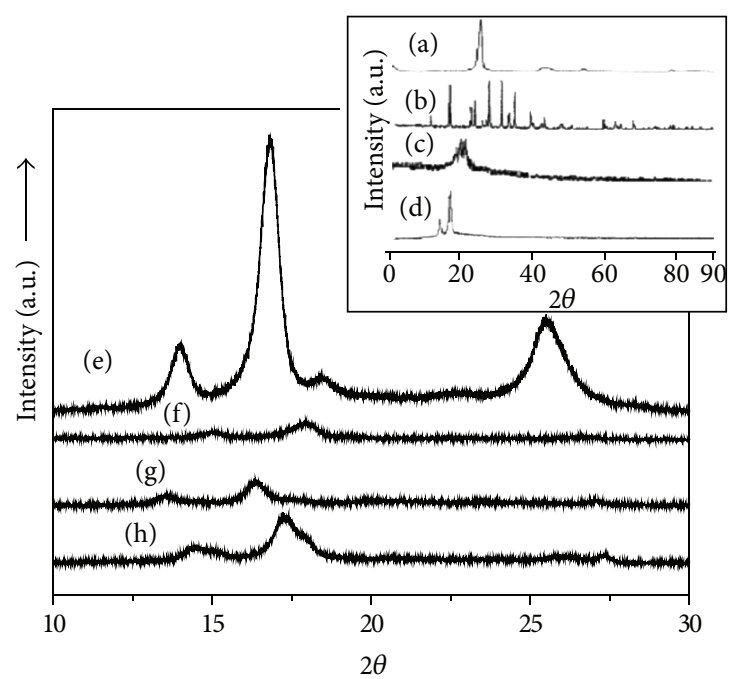

FIGURE 3: X-ray diffractograms of (a) pure MWNT, (b) pure $\mathrm{NH}_{4} \mathrm{SCN}$, (c) DMSO casted PVA gel film, and (d) DMSO casted PVA: $\mathrm{NH}_{4} \mathrm{SCN}$ gel electrolyte are shown in INSET and its composite containing (e) $2 \mathrm{wt} \%$, (f) $4 \mathrm{wt} \%$, (g) $6 \mathrm{wt} \%$, and (h) $8 \mathrm{wt} \% \mathrm{MWNT}$ filler.

diffraction study, it is thus concluded that MWNTs upon dispersal significantly improves the amorphous behavior of polymer electrolyte.

Degree of crystallinity Xc of electrolytes with respect to MWNT was estimated to ascertain improvement in amorphous nature [12] presuming filler to be fully crystalline (Table 2). The structural parameter calculated for pristine electrolyte and MWNT doped electrolytes from Scherrer's equation are given in Table 2 . It is observed that the crystallite size and degree of crystallinity decreases upon addition of MWNT in pristine electrolyte. Though the average crystallite size increases marginally with MWNT loadings, degree of crystallinity dips continuously. These observations ascertain enhancement in the degree of disorder and amorphousness
TABLE 2: Average crystallite size, crystallinity of nancomposite polymer electrolyte system (PVA: $\mathrm{NH}_{4} \mathrm{SCN}$ :DMSO:MWNT).

\begin{tabular}{cccc}
\hline SN & $\begin{array}{c}\text { Concentration of } \\
\text { MWNT content } \\
\text { in pristine electrolyte }\end{array}$ & $\begin{array}{c}\text { Average } \\
\text { crystallite } \\
\text { size }(\mathrm{nm})\end{array}$ & $\begin{array}{c}\text { Degree of } \\
\text { crystallinity } \\
\text { Xc (\%) }\end{array}$ \\
\hline 1 & 2 wt\% & 33.4 & 26 \\
2 & 4 wt $\%$ & 35.1 & 9.1 \\
3 & 6 wt\% & 37.5 & 5.2 \\
4 & 8 wt $\%$ & 37.7 & 3.2 \\
\hline
\end{tabular}

in the polymeric membranes on loading electrolytes with MWNTs [20, 25]. Further average crystallite size of nanomatric size is restricted for all the samples indicating formation of nanocomposite electrolytes subsequent to MWNT dispersal.

3.3. Frequency Independent (d.c.) Conductivity. Figure 4 shows the effect of dispersal of MWNTs on the ion conduction properties of polymer composite dried gel electrolytes. It is apparent from this figure that the conductivity of composite electrolyte improves slightly in magnitude till $2 \mathrm{wt} \%$ and thereafter decreases till $4 \mathrm{wt} \%$ before rising again and ultimately falling off beyond $6 \mathrm{wt} \%$ MWNT concentration in composite electrolyte. This feature is typical of nanocomposite polymer electrolytes [25-28]. XRD studies have shown intercalation of MWNTs in pristine electrolyte. This intercalation is likely to promote dissociation of salt leading to enhancement in the value of carrier concentration thereby causing increase in conductivity values $[12,14]$. Such a conclusion is envisaged on the fact that Lewis acid-base interactions between the heterogeneously dispersed filler surface and anions compete with interactions between cations and anions promoting salt dissociation via a sort of ionfiller complex formations [29]. Polymer-filler-salt interaction has also been noticed in XRD profiles (Figure 3) through shifting of diffraction peaks in the presence of filler particles (Section 3.2). At higher concentration of nanofillers, the nano 


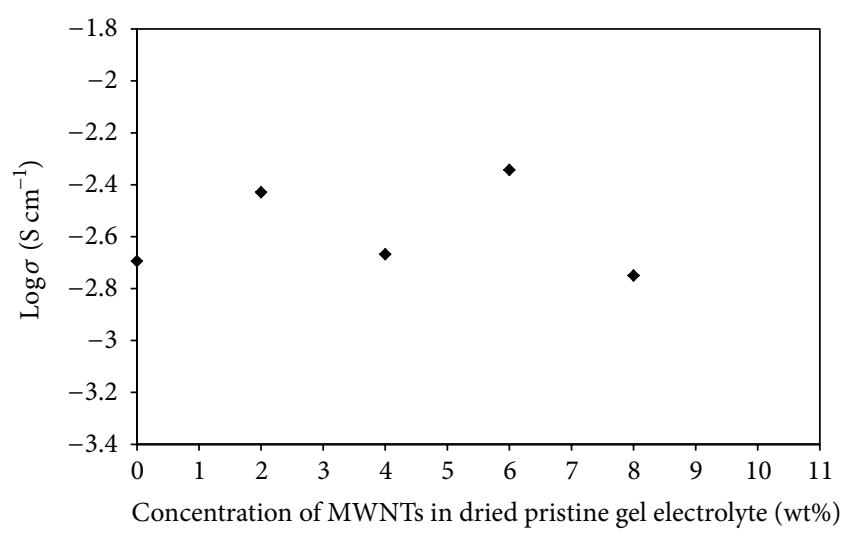

FIGURE 4: Variation of conductivity of nanocomposite polymer electrolytes with MWNT filler concentration (at room temperature).

filler particles serve as cross linking centres for polymer segments causing immobility of polymer chains in accordance with Tsagarapolous model [14]. Thus conductivity drops significantly. At intermediate concentrations the decrease in conductivity may be due to pairing effect/re-association of free ions $[1,5,21]$. The second conductivity maxima is related to formation of highly conducting interfacial layer between MWNT and gel electrolyte caused by filler salt interaction which dominates over ion pairing effect $[6,11,14,24]$.

Ionic conductivity of polymer electrolytes is known to augment with rise of temperature and the behaviour has been rationalised by recognizing free volume model [30]. This in turn positively affects the mobility of ion and polymer segments resulting in rise of bulk conductivity. The amount of increase in conductivity thus depends upon the free volume around the polymer chain. Present investigations too show an enhancement in bulk conductivity of composite system with increasing temperature (Figure 5). Arrhenius and VogelTammam-Fulcher (VTF) relation [31] have been successfully used to describe temperature dependence of ionic conductivity of polymeric systems. In the low temperature regime (below $50^{\circ} \mathrm{C}$ ) segmental motion of chain segments obstructs the easy motion of charge carriers as polymer enters into viscoelastic phase $[5,32]$. Hence, conductivity rise is limited. Further as the filler concentration increases in composite electrolytes, conductivity values significantly drop down owing to increasing tortuous pathways created by agglomeration of filler particles [13]. Thus, it seems that the nanocomposite solid electrolytes membranes behave as an ionic solid in which the mechanism of ion diffusion involves ion-polymer segment coupling such as conventional polymer electrolytes [33].

3.4. Frequency Dependent (a.c.) Conductivity. Analysis of frequency dependent electrical response of solid electrolytes with disordered structure is a versatile approach for understanding the nature of ionic transport. The variation of a.c. conductivity for pristine electrolyte and nanocomposite polymer electrolyte doped with two MWNT loadings as a function of frequency is shown in Figure 6. It is apparent that a.c. conductivity increases with frequency in the low

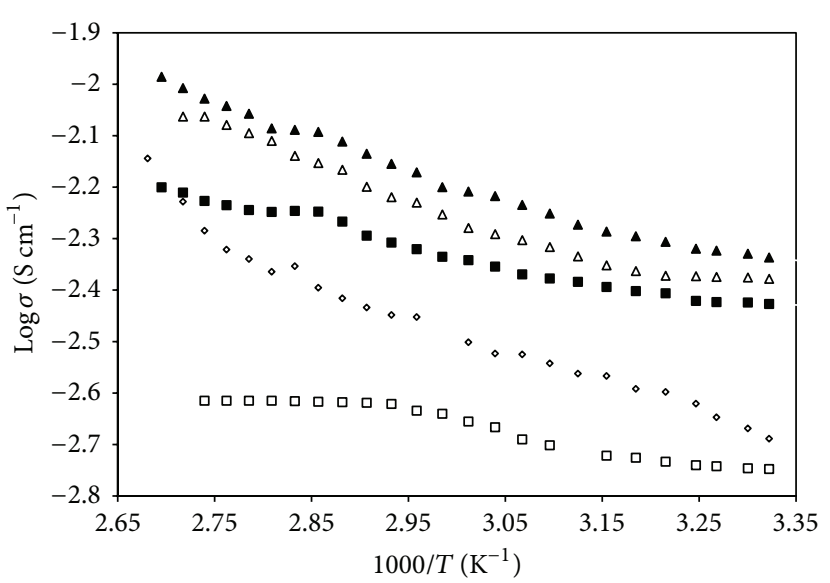

FIgURE 5: Temperature dependence conductivity of nanocomposite

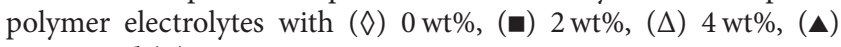
$6 \mathrm{wt} \%$, and (口) $8 \mathrm{wt} \%$ MWNT contents.

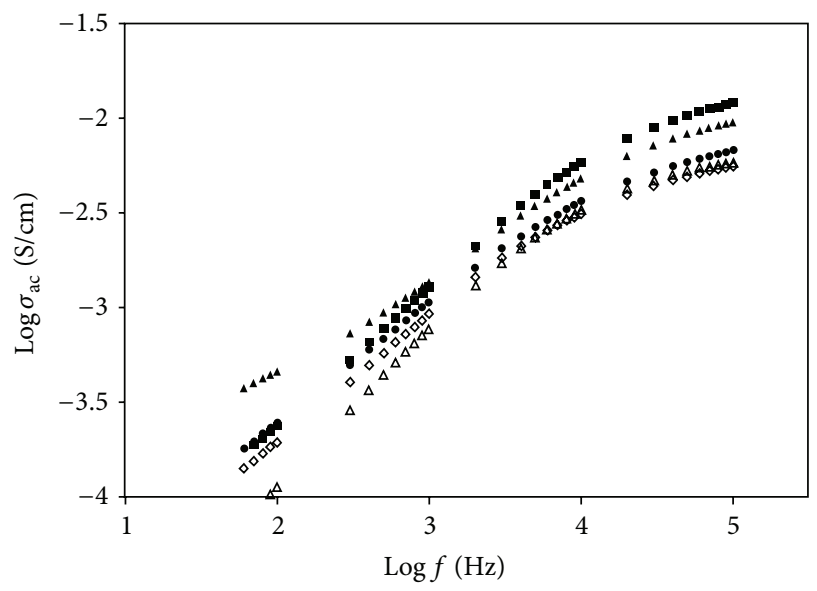

FIGURE 6: Variation of a.c. conductivity with frequency for nanocomposite polymer electrolyte containing $(\Delta) 0 \mathrm{wt} . \%$, (•) $2 \mathrm{wt} . \%$, (ム) 4 wt.\%, (ロ) 6 wt.\%, and (口) 8 wt.\% MWNT contents.

frequency regime followed by a nearly frequency independent behavior in the high frequency regime for all electrolyte systems. The increasing conductivity behavior is connected to the electrode-electrolyte phenomena that is, it results from electrode polarization effects [13], while saturation like behavior results from the failure of hopping of ions from one site to another with increasing frequency. The overall a.c. conductivity can be best described by Jonscher's power law expressed as

$$
\sigma_{\mathrm{ac}}(\omega)=\sigma_{0}+A \omega^{p}
$$

where $\sigma_{0}$ is the d.c. conductivity (the extrapolation of plateau region to zero frequency gives the value of dc conductivity), A the preexponential factor and $p$ the fractional exponent between 0 and 1 . This kind of behavior has been reported for wide range of nanocomposite polymer electrolytes [14, 17] and also for PVA:DMSO: $\mathrm{NH}_{4} \mathrm{SCN}: \mathrm{Al}_{2} \mathrm{O}_{3}$ electrolytes. It is observed that the increase in filler content enhances a.c. conductivity. The calculated value of power law exponent $(p)$, 
TABLE 3: Values of $\sigma_{0}, A$, and $p$ for PVA: $\mathrm{NH}_{4}$ SCN:MWNT nanocomposite polymer electrolyte.

\begin{tabular}{lcccc}
\hline SN & $\begin{array}{c}\text { Concentration of MWNT } \\
\text { content in pristine } \\
\text { electrolyte }\end{array}$ & $\sigma_{0}(\mathrm{~S} / \mathrm{cm})$ & $A$ & $p$ \\
\hline 1 & $2 \mathrm{wt} \%$ & $1.3 \times 10^{-3}$ & 0.051 & 0.560 \\
2 & $4 \mathrm{wt} \%$ & $3.2 \times 10^{-3}$ & 0.058 & 0.563 \\
3 & $6 \mathrm{wt} \%$ & $4.1 \times 10^{-3}$ & 0.042 & 0.571 \\
4 & $8 \mathrm{wt} \%$ & $8.6 \times 10^{-4}$ & 0.059 & 0.610 \\
\hline
\end{tabular}

generally for ionic conductor can be in between 1.0 and 0.5 , indicating the ideal long-range pathway and diffusion limited hopping [34]. If $p=0$ the motion is completely random and independent Debye like ion hops. In the present case, the exponent factor was found to be 0.56 for pristine electrolyte and it increases to 0.61 for $6 \mathrm{wt} \%$ MWNT loading (Table 3) which suggest supportive role played by MWNT particles in ion conduction. The observed frequency dispersion for different composite can be rationalized with the help of jump relaxation model [35] since the dynamical effect of polymer host caused by segmental renewal rates, is less significant below microwave frequencies. According to this model, an ion can hop from a site to neighbouring vacant site successfully to contribute to conductivity. At high frequencies the probability for ion to hop back increases due to short time periods. This forward-backward hopping at high frequencies together with relaxation of dynamic cage potential seems to be responsible for high frequency plateau $[13,35]$. It has been observed that the maximum value of a.c. conductivity was found to be $4.1 \times 10^{-3} \mathrm{~S} / \mathrm{cm}$ for $6 \mathrm{wt} \%$ MWNTs concentration at room temperature.

\section{Conclusions}

The objective of this study was to investigate the role of MWNT filler on the dynamic mechanical and electrical properties of the PVA: $\mathrm{NH}_{4} \mathrm{SCN}$ :DMSO system. Experimental investigations show that dynamical $T_{g}$ values (shift from 102 to $87.6^{\circ} \mathrm{C}$ ) and other mechanical relaxation parameters like storage and loss modulus of nanocomposite electrolytes are affected by the presence of filler. Also the mechanical strength and stability of polymer electrolytes is immensely improved in the presence of MWNT filler (increase in storage modulus in magnitude). XRD patterns exhibit broadening of diffraction patterns of composite system on addition of fillers suggesting improved amorphousness (decrease in crystallinity from $26 \%$ to $3.2 \%$; Table 2). Addition of MWNT in PVA: $\mathrm{NH}_{4} \mathrm{SCN}$ :DMSO system improves its ionic conductivity which is associated to improved amorphous behaviour of films. The optimum ionic conductivity is achieved $(4.5 \times$ $10^{-3} \mathrm{~S} / \mathrm{cm}$ ) for $6 \mathrm{wt} \%$ MWNT loaded membranes. Such high ionically conductive membranes with superior mechanical stability suggest their applicability in electrochemical devices particularly high performance solid state batteries.

\section{Conflict of Interests}

The authors declare that there is no conflict of interests regarding the publication of this paper.

\section{References}

[1] S. Chandra, S. S. Sekhon, and N. Arora, "PMMA based protonic polymer gel electrolytes," Ionics, vol. 6, no. 1-2, pp. 112-118, 2000.

[2] S. L. Agrawal and A. Awadhia, "DSC and conductivity studies on PVA based proton conducting gel electrolytes," Bulletin of Materials Science, vol. 27, no. 6, pp. 523-527, 2004.

[3] F. M. Gray, Solid Polymer Electrolytes-Fundamental and Technological Applications, Wiley, New York, NY, USA, 1991.

[4] A. Bhide and K. Hariharan, "Ionic transport studies on $(\mathrm{PEO})_{6}: \mathrm{NaPO}_{3}$ polymer electrolyte plasticized with $\mathrm{PEG}_{400}$," European Polymer Journal, vol. 43, no. 10, pp. 4253-4270, 2007.

[5] A. Awadhia and S. L. Agrawal, "Structural, thermal and electrical characterizations of PVA:DMSO: $\mathrm{NH}_{4} \mathrm{SCN}$ gel electrolytes," Solid State Ionics, vol. 178, no. 13-14, pp. 951-958, 2007.

[6] K. Pandey, M. M. Dwivedi, N. Asthana, M. Singh, and S. L. Agrawal, "Structural and ion transport studies in (100 $-x) \mathrm{PVdF}+{ }_{x} \mathrm{NH}_{4} \mathrm{SCN}$ gel electrolyte," Materials Sciences and Application, vol. 2, pp. 721-728, 2011.

[7] C. S. Ramya, S. Selvasekarapandian, T. Savitha et al., "Conductivity and thermal behavior of proton conducting polymer electrolyte based on poly (N-vinyl pyrrolidone)," European Polymer Journal, vol. 42, no. 10, pp. 2672-2677, 2006.

[8] S. L. Agrawal and P. K. Shukla, "Structure and electrical characterization of polymeric electrolytes: PVA: $\mathrm{NH}_{4} \mathrm{SCN}$ system," Indian Journal of Pure \& Applied Physics, vol. 38, no. 1, pp. 5361, 2000.

[9] F. Croce, G. B. Appetecchi, L. Persi, and B. Scrosati, "Nanocomposite polymer electrolytes for lithium batteries," Nature, vol. 394, no. 6692, pp. 456-458, 1998.

[10] G. B. Appetecchi, S. Scaccia, and S. Passerini, "Investigation on the stability of the lithium-polymer electrolyte interface," Journal of the Electrochemical Society, vol. 147, no. 12, pp. 44484452, 2000.

[11] S. L. Agrawal, N. Rai, and N. Chand, "Dynamic mechanical, DSC, and electrical investigations on nano $\mathrm{Al}_{2} \mathrm{O}_{3}$ FILLED PVA: $\mathrm{NH}_{4} \mathrm{SCN}$ :DMSO polymer composite dried gel electrolytes," International Journal of Polymeric Materials, vol. 62, no. 2, pp. 61-67, 2013.

[12] N. Chand, N. Rai, S. L. Agrawal, and S. K. Patel, "Morphology, thermal, electrical and electrochemical stability of nano aluminium-oxide-filled polyvinyl alcohol composite gel electrolyte," Bulletin of Materials Science, vol. 34, no. 7, pp. 12971304, 2011.

[13] S. L. Agrawal, M. Singh, M. M. Dwivedi, M. Tripathi, and K. Pandey, "Dielectric relaxation studies on $\left[\mathrm{PEO}-\mathrm{SiO}_{2}\right]: \mathrm{NH}_{4} \mathrm{SCN}$ nanocomposite polymer electrolyte films," Journal of Materials Science, vol. 44, no. 22, pp. 6060-6068, 2009.

[14] S. L. Agrawal, N. Rai, T. S. Natarajan, and N. Chand, "Electrical characterization of PVA-based nanocomposite electrolyte nanofibre mats doped with a multiwalled carbon nanotube," Ionics, vol. 19, no. 1, pp. 145-154, 2013.

[15] M. Endo, T. Hayashi, and Y.-A. Kim, "Large-scale production of carbon nanotubes and their applications," Pure and Applied Chemistry, vol. 78, no. 9, pp. 1703-1713, 2006. 
[16] M. J. O'Connell, Carbon Nanotube Properties and Applications, CRC Press, New York, NY, USA, 2006.

[17] M. Abdullah, W. Lenggoro, and K. Okuyama, "Polymer electrolyte nanocomposites," in Encyclopedia of Nanoscience and Nanotechnology, H. S. Nalwa, Ed., vol. 8, p. 731, American Scientific Publishers, 2004.

[18] E. Zawadzka, R. Kulinski, B. Szubzda, and B. Mazurek, "Polyaniline-multi-walled carbon nanotube shell-core composite as an electrode material in supercapacitors," Materials Science-Poland, vol. 27, pp. 1271-1278, 2009.

[19] D. López, I. Cendoya, F. Torres, J. Tejada, and C. Mijangos, "Preparation and characterization of poly(vinyl alcohol)-based magnetic nanocomposites. 1. Thermal and mechanical properties," Journal of Applied Polymer Science, vol. 82, no. 13, pp. 32153222, 2001.

[20] D. R. Paul and L. M. Robeson, "Polymer nanotechnology: nanocomposites," Polymer, vol. 49, no. 15, pp. 3187-3204, 2008.

[21] J. B. Kerr, Y. B. Han, G. Liu, C. Reeder, J. Xie, and X. Sun, "Interfacial behavior of polymer electrolytes," Paper LBNL53141, Lawrence Berkley National Laboratory, Berkeley, Calif, USA, 2003.

[22] D. K. Pradhan, R. N. P. Choudhary, B. K. Samantaray, N. K. Karan, and R. S. Katiyar, "Effect of plasticizer on structural and electrical properties of polymer nanocompsoite electrolytes," International Journal of Electrochemical Science, vol. 2, pp. 861871, 2007.

[23] S. U. Patil, S. S. Yawale, and S. P. Yawale, "Conductivity study of $\mathrm{PEO}-\mathrm{LiClO}_{4}$ polymer electrolyte doped with $\mathrm{ZnO}$ nanocomposite ceramic filler," Bulletin of Materials Science, vol. 37, no. 6, pp. 1403-1409, 2014.

[24] A. L. Sharma and A. K. Thakur, "Polymer-ion-clay interaction based model for ion conduction in intercalation-type polymer nanocomposite," Ionics, vol. 16, no. 4, pp. 339-350, 2010.

[25] H. Ardebili, C. Tang, K. Hackenberg, Q. Fu, P. M. Ajayan, and $\mathrm{H}$. Ardebili, "High ion conducting polymer nanocomposite electrolytes using hybrid nanofillers," Nano Letters, vol. 12, no. 3, pp. 1152-1156, 2012.

[26] N. Lakshmi and S. Chandra, "Proton conducting composites of heteropolyacid hydrates (phosphomolybdic and phosphotungstic acids) dispersed with insulating $\mathrm{Al}_{2} \mathrm{O}_{3}$," Physica Status Solidi (A), vol. 186, pp. 383-399, 2001.

[27] R. C. Agrawal and R. K. Gupta, "Superionic solids: composite electrolyte phase-an overview," Journal of Materials Science, vol. 34, no. 6, pp. 1131-1162, 1999.

[28] T. Miyamoto and K. Shibayama, "Free-volume model for ionic conductivity in polymers," Journal of Applied Physics, vol. 44, no. 12, pp. 5372-5376, 1973.

[29] R. C. Agrawal and Y. K. Mahipal, "Study of electrical and electrochemical behaviour on hot-press synthesized nanocomposite polymer electrolyte (NCPE) membranes: [(70PEO: $\left.30 \mathrm{KNO}_{3}\right)+\mathrm{x} \mathrm{SiO}_{2}$ ]," International Journal of Electrochemical Science, vol. 6, pp. 867-881, 2011.

[30] D. Kumar and S. A. J. Hashmi, "Ion transport and ionfiller-polymer interaction in poly(methyl methacrylate)-based, sodium ion conducting, gel polymer electrolytes dispersed with silica nanoparticles," Journal of Power Sources, vol. 195, no. 15, pp. 5101-5108, 2010.

[31] P. K. Shukla and S. L. Agrawal, "Influence of solvent on the ionic conductivity of PVA- $\mathrm{NH}_{4} \mathrm{SCN}$ complex," Bulletin of Electrochemical, vol. 12, no. 11-12, pp. 732-737, 1996.
[32] M. Sivakumar, R. Subadevi, S. Rajendran, N.-L. Wu, and J.-Y. Lee, "Electrochemical studies on [( $1-x)$ PVA- $x$ PMMA] solid polymer blend electrolytes complexed with $\mathrm{LiBF}_{4}$," Materials Chemistry and Physics, vol. 97, no. 2-3, pp. 330-336, 2006.

[33] S. H. Chung, K. Such, W. Wieczorek, and J. R. Stevens, "Analysis of ionic conductivity in polymer electrolytes," Journal of Polymer Science Part B: Polymer Physics, vol. 32, no. 16, pp. 2733-2741, 1994.

[34] V. Gupta and A. Mansingh, "Hopping conduction in insulating rf-sputtered zinc oxide films," Physical Review B, vol. 49, no. 3, pp. 1989-1995, 1994.

[35] K. Funke, "Jump relaxation in solid electrolytes," Progress in Solid State Chemistry, vol. 22, no. 2, pp. 111-195, 1993. 

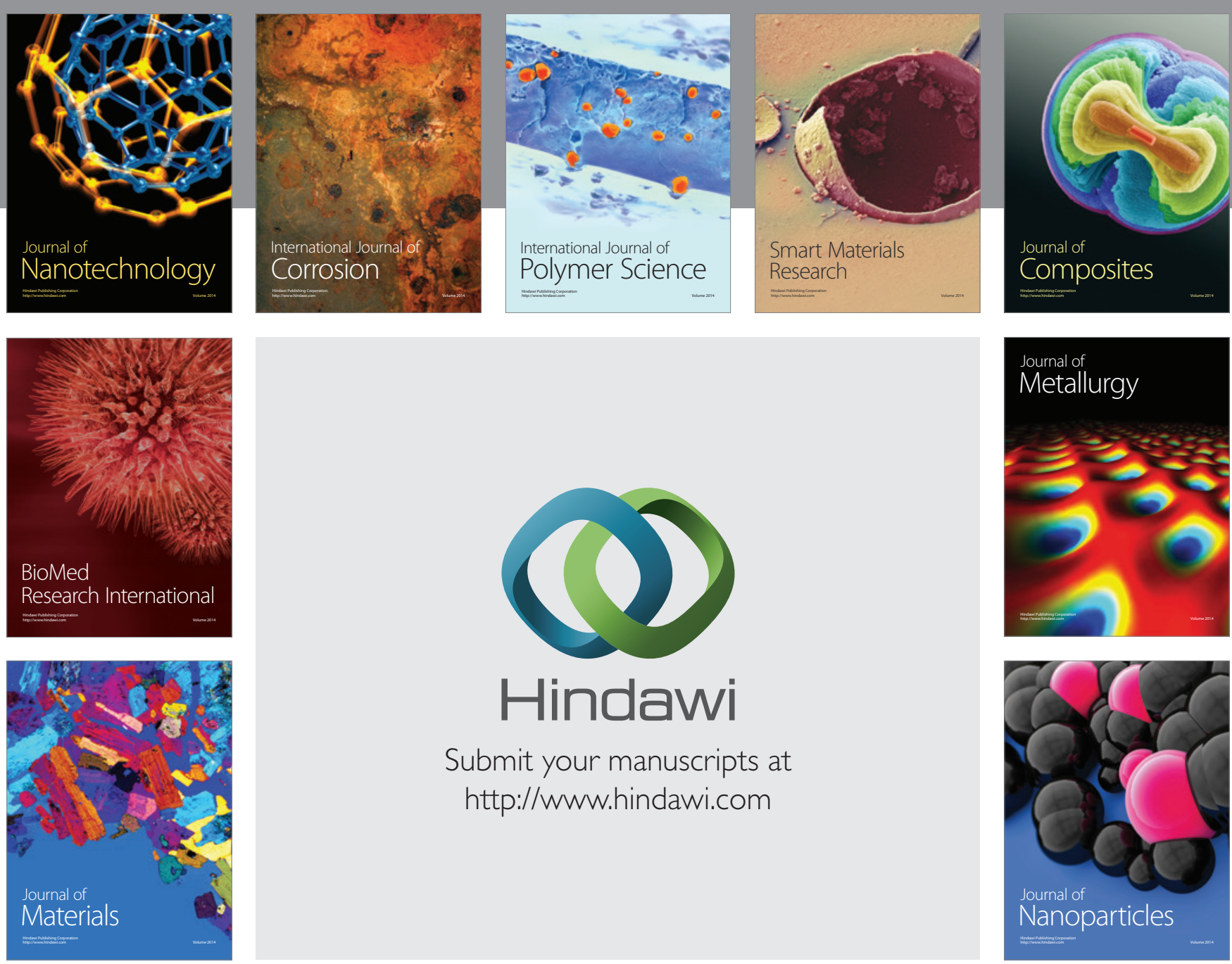

Submit your manuscripts at http://www.hindawi.com
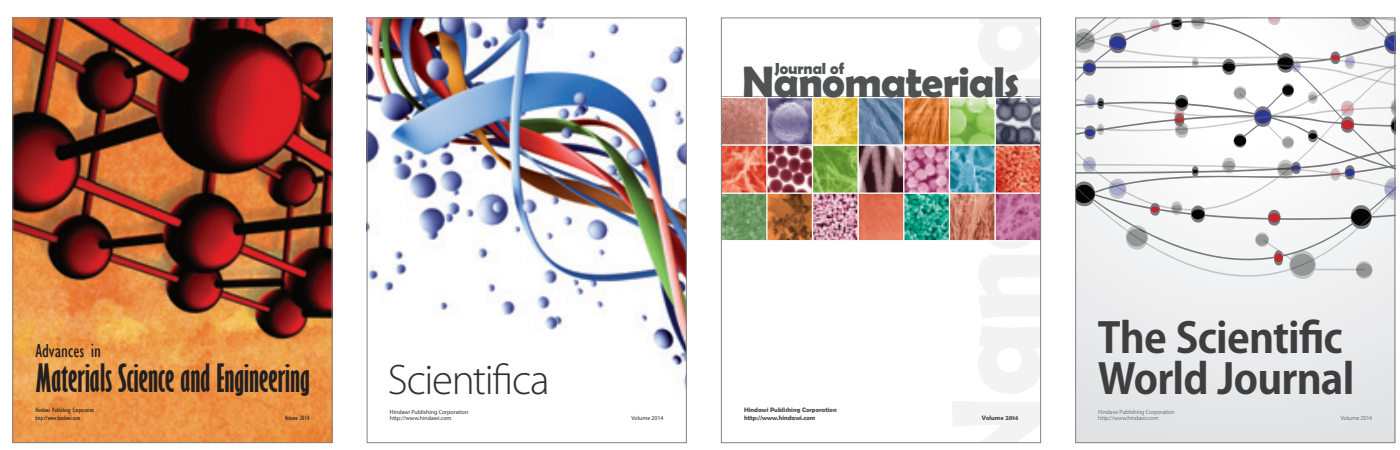

\section{The Scientific World Journal}
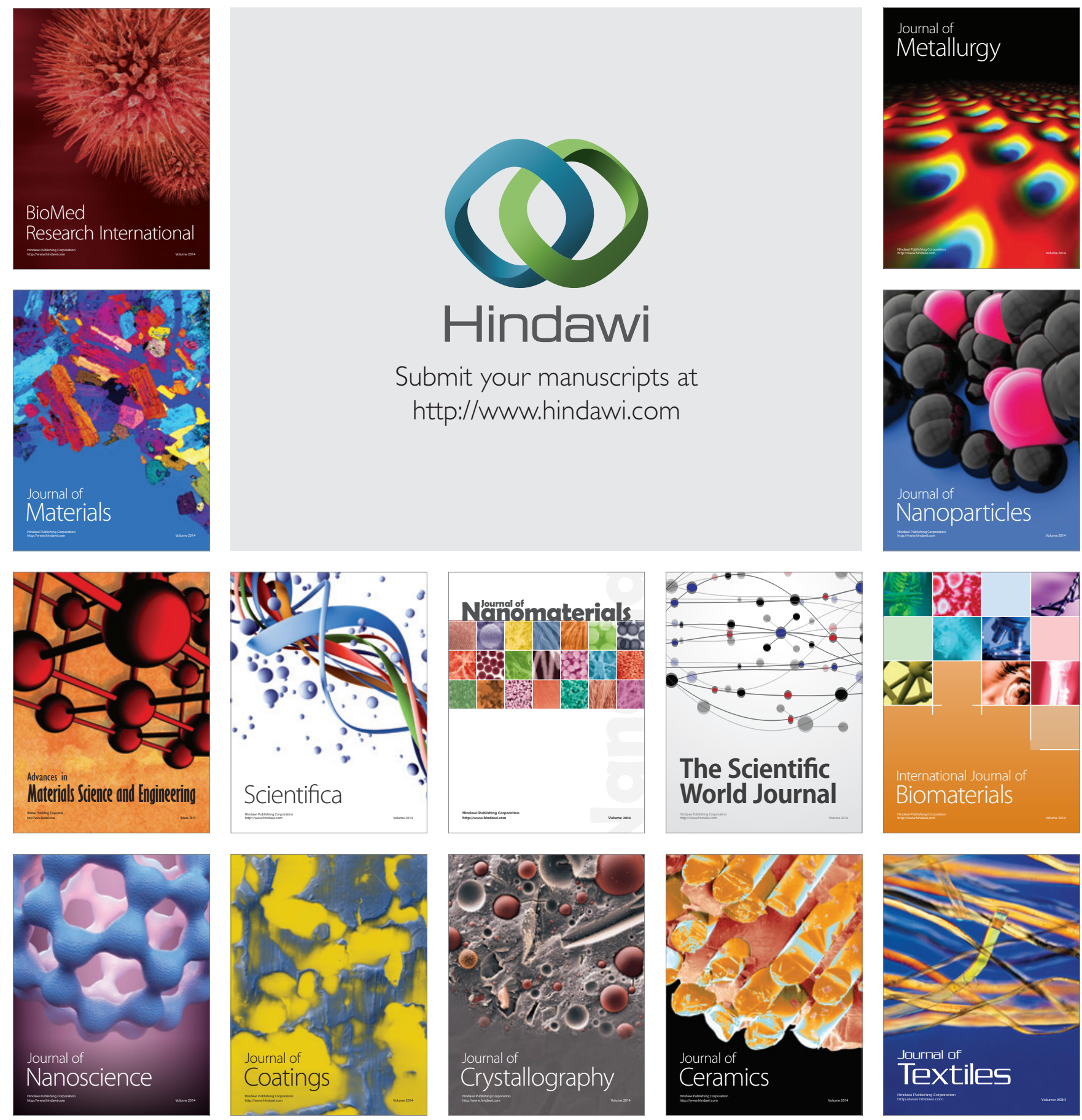